\title{
3-Thienyl/benzothienylchromones. Synthesis and properties
}

\author{
Natalia V. Gorbulenko*, Tatiana V. Shokol, Vladimir P. Khilya \\ Department of Chemistry, Taras Shevchenko National University of Kyiv, \\ Volodymyrska Street, 64/13, Kyiv 01601, Ukraine \\ ngorbulenko@ukr.net
}

Keywords: 3-hetarylchromones, $\alpha$-hetaryl-2-hydroxyacetophenones, chromones, thiophene and benzothiophene compounds, cyclization reactions, coupling reactions.

This mini-review for the first time summarizes and systematizes all the data available in the literature on the synthesis and properties of 3-thienyl/benzothienylchromones, starting from 1960. Two main approaches to the formation of target structures are presented. The conditions of cyclization reactions, oxidative rearrangement, transition metals catalyzed $\mathrm{CH}$ activation and annulation reactions, etc. are discussed. Testing data for some types of biological activity of a number of the 3-thienyl/benzothienylchromones and the products of their transformation into the pyrazole cycle are given.

\section{Introduction}

One of the most promising ways to create new biologically active compounds for medical chemistry is certainly the synthesis of analogues of natural low molecular weight bioregulators. A synthetically realized combination of natural benzopyrone structures, such as "drug-like natural matrices", with pharmacophores such as S-, O-, N-containing heterocycles, which are structural elements of many not only synthetic, but also endogenous biologically active compounds, has led to fundamentally new structures - the so-called "double drugs", a potential bispharmacophore drugs.

Modification of isoflavonoids by replacing the aryl substituent with a heterocyclic substituent in the classical isoflavone structure was first successfully implemented in 1960 [1]. The described thienyl analogues of estrogenic isoflavones turned out to be the first representatives of 3-hetarylchromones and stimulated the further development of synthesis methods and the study of the properties of this fundamentally new type of compounds. Against the background of a consistently high number of scientific and patent publications, review articles on 3-hetarylchromones with $\mathrm{N}$ - and $\mathrm{O}$ containing heterocycles, there are relatively few materials on 3-hetarylchromones with Scontaining heterocycles, mostly published after 2000 and, as far as is known, were not systematized.

To a certain extent, the observed increase in the publication activity of 3-hetarylchromones 
with S-containing heterocycles is associated with the increased use of cross-coupling reactions for the preparation of heterocyclic compounds of various structures over the past two decades [2]. Among all these reactions catalyzed by transition metals, the SuzukiMiyaura reaction, which uses boronic acids or esters, remains the method of choice. Advances in the synthesis and study of the reactivity of new heterocyclic boronic acids make it possible to create target libraries that are now mandatory in medical chemistry [3].

This review summarizes the results of research for the synthesis and biological screening of 3-thienyl/benzothienylchromones. Two main approaches used in the synthesis of target 3-hetarylchromones, such as cyclization of S-containing ring synthons into chromone system or introduction of an S-containing heterocycle to the chromone system are highlighted. Chemical properties were represented only by a single example of a reaction with hydrazine hydrate. The range of biological action of the target 3hetarylchromones and some their transformation products into the pyrazole cycle was determined.

\section{Synthesis of 3-thienylchromones by the}

formation of the pyrone cycle from synthons, including S-containing heterocycle

The first synthesized heteroanalogs of isoflavones were thienyl derivatives 1-3 obtained upon cyclization of $\alpha$-(2-thienyl)-2,4,6- trihydroxyacetophenone 4 with ethyl oxalyl chloride and subsequent transformations of 2ethoxycarbonyl-3-(2-thienyl)-5,7-

dihydroxychromone $\mathbf{1}$ on the ethoxycarbonyl group (hydrolysis and decarboxylation) [1] (Scheme 1).
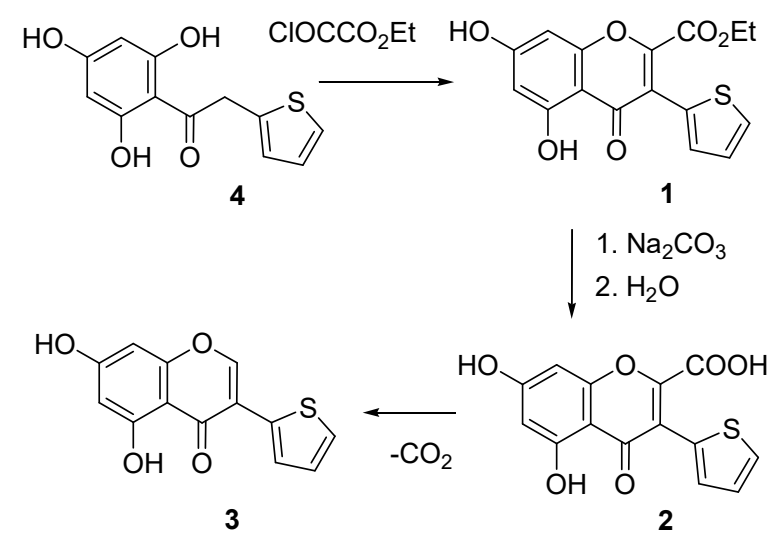

Scheme 1. The synthesis of 2-(un)substituted-3-(2thienyl)-5,7-dihydroxychromones

The patent [4] discloses the synthesis of 5(7-hydroxy-4-oxo-2-trifluoromethyl-4Hchromen-3-yl)thiophen-2- and thiophene-3carboxylic acids 5, 6 and their methyl esters 7, 8 by cyclization of the corresponding $\alpha-(2-$ thienyl)-2,4-dihydroxyacetophenones $\mathbf{9 , 1 0}$ with trifluoroacetic acid in the presence of triethylamine in dichloromethane at $0 \quad{ }^{\circ} \mathrm{C}$ (Scheme 2). 

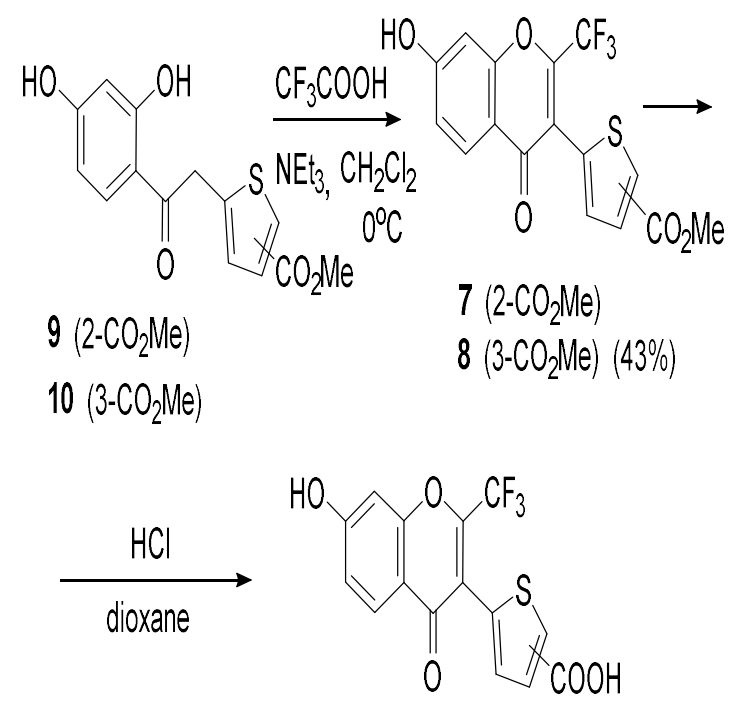

$5(2-\mathrm{COOH})(76 \%)$
$6(3-\mathrm{COOH})(65 \%)$

Scheme 2. The synthesis of 5-(7-hydroxy-4-oxo-2trifluoromethyl)-4H-chromen-3-yl)thiophen-2thiophene-3-carboxylic acids and their methyl esters

The thienyl derivatives of benzodipyranone of an asymmetric and symmetrical structure benzodipyrano-4,10-dione $\mathbf{1 1}$ and benzodipyrano-4,6-dione 12 were obtained by the Vilsmeier-Haack reaction from the condensation product of phloroglucinol and 2thienylacetonitrile $\mathbf{1 3}$ with methanesulfonyl chloride and $\mathrm{N}, \mathrm{N}$-dimethylformamide in boron trifluoride etherate at $120{ }^{\circ} \mathrm{C}$ [5] (Scheme 3).

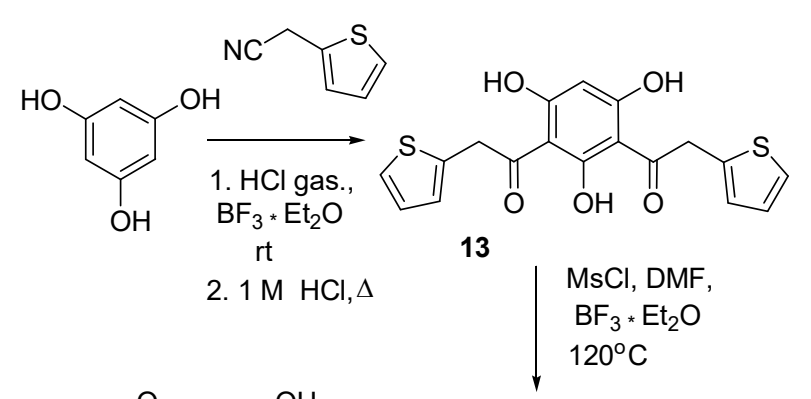<smiles></smiles>

Scheme 3. The synthesis of thienyl derivatives of benzodipyrano-4,10-dione and benzodipyrano-4,6-dione
The work [6] described examples of the oxidative rearrangement of a 2'-hydrochalcone with various substituents $(\mathrm{R})$ in ring $\mathrm{B}$ using 1H-1-hydroxy-5-methyl-1,2,3-benzodioxathiol 3,3-dioxide (HMBI). Direct conversion took place by boiling in methanol, without the need for preliminary protection of the 2'-hydroxy group of the chalcone. Derivatives of terminal isoflavones are formed as the main product, and 2,3-dihydro-2-R-3-benzofurancarboxylic acid methyl esters and the corresponding flavone derivatives are formed in low yields. In the case of a 2'-hydroxychalcone with a thienyl substituent in ring B 14, 3-(2-thienyl) chromone 15 was obtained in $34 \%$ yield, and the yields of 2,3-dihydro-2-(2-thienyl)-3-

benzofurancarboxylic acid methyl ester 16 and 2-(2-thienyl)chromone 17 were determined to be $6 \%$ and $0 \%$, respectively, based on ${ }^{1} \mathrm{H}$ NMR spectroscopy data, using the internal standard in a separate experiment (Scheme 4).

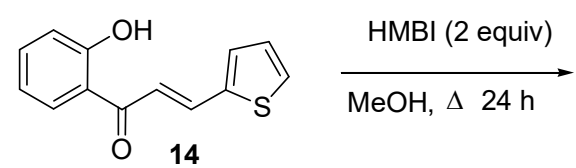

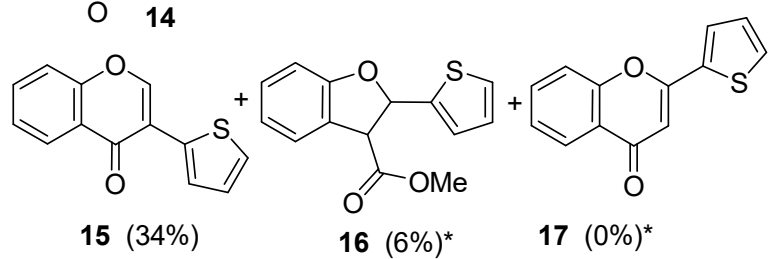

Scheme 4. The synthesis of 3-(2-thienyl)chromone

The catalyzed by transition metals reactions of $\mathrm{CH}$-activation and annulation are an effective tool for the synthesis of 3-hetarylchromone derivatives. The role of the catalyst/catalytic 
complex is not only to accelerate the speed of the process, but can also affect the selectivity of the chemical reaction.

In the coupling reaction of 1-(2-tertbutyldimethylsilyloxy)phenyl-3-phenyl-2-

propyn-1-one $\mathbf{1 8}$ with 2-iodothiophene in absolute methanol in the presence of catalytic amounts of $\mathrm{Pd}\left(\mathrm{PPh}_{3}\right)_{4}$ and $\mathrm{CuI}$ and $\mathrm{K}_{2} \mathrm{CO}_{3}$ as base 2-(1-thienyl-1-phenylmethylene) benzofuranone 19 and 2-phenyl-3thienylchromone 20 were obtained [7] (Scheme 5).
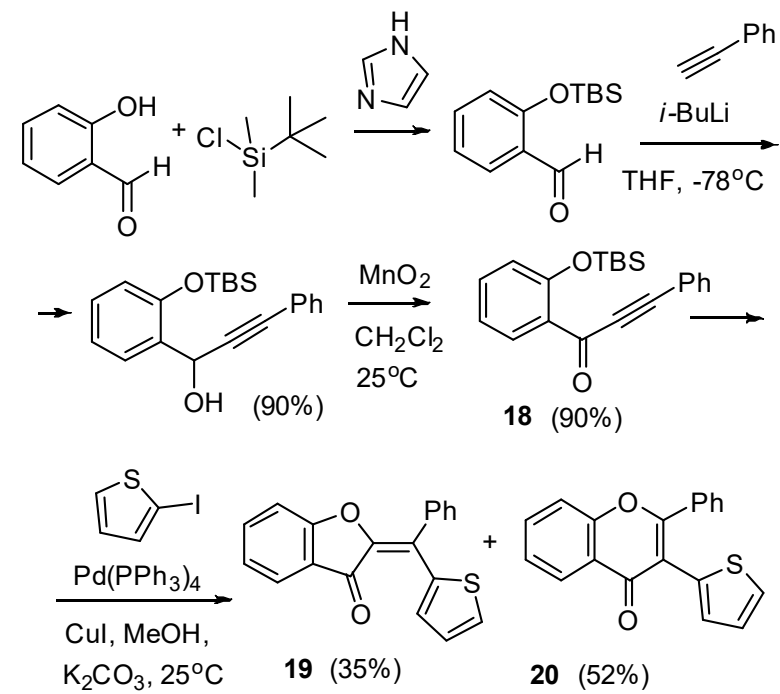

Scheme 5. The synthesis of 2-phenyl-3-(2thienyl)chromone

A new effective method for the synthesis of 3substituted 2-aminochromones promoted by $\mathrm{Sn}(\mathrm{IV})$ annulation of ynamides with 2-methoxy aroyl chlorides under mild conditions was used to obtain 3-(2-thienyl)chromone having substituted amino group at C-2 21. This method provides concomitant construction of $\mathrm{C}-\mathrm{C}$ and $\mathrm{C}-\mathrm{O}$ bonds between ynamides and 2-methoxy aroyl chlorides according to the tandem Friedel-
Crafts acylation/Michael addition/ elimination strategy [8] (Scheme 6).

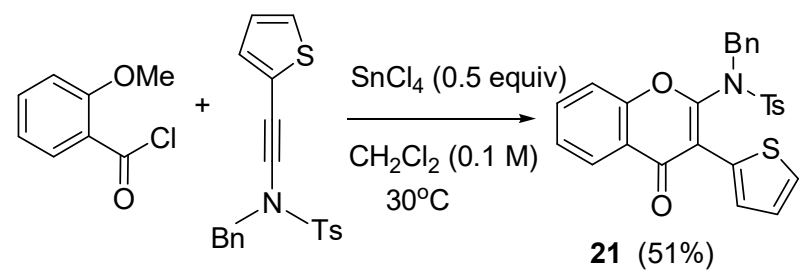

Scheme 6. The synthesis of 3-(2-thienyl)chromone having substituted amino group at $\mathrm{C}-2$

By direct oxidative coupling of salicylic aldehyde 22 with bis(2-thienyl)acetylene $\mathbf{2 3}$ in the presence of a rhodium catalyst, cyclopentadiene ligand and copper(II) acetate in $o$-xylene at $140{ }^{\circ} \mathrm{C}$ in nitrogen atmosphere within 4 hours, 2,3-bis(2-thienyl)chromone 24 was obtained [9] (Scheme 7).

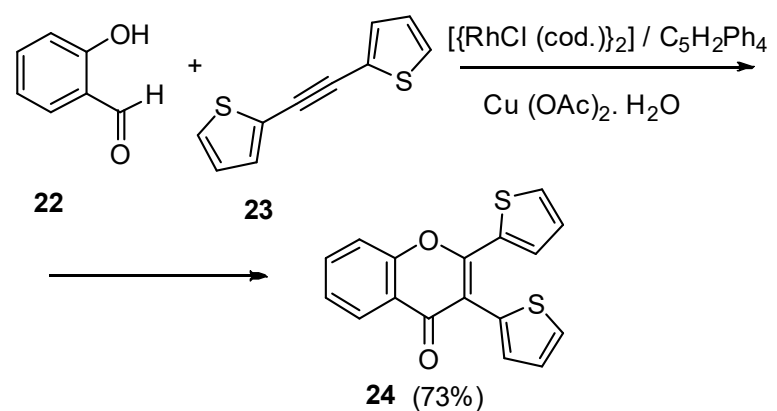

Scheme 7. The synthesis of 2,3-bis(2-thienyl)chromone

The isomeric thienyl derivatives of chromone 25 and 26 were obtained by the annulation reaction of salicylic aldehyde $\mathbf{2 2}$ with disubstituted alkyne 27 using the newly developed $\mathrm{Ru}(\mathrm{II})$ catalyst system in tert-amyl alcohol at $80{ }^{\circ} \mathrm{C}$ in air within 12 hours and were separated by column chromatography on silica gel [10] (Scheme 8). 


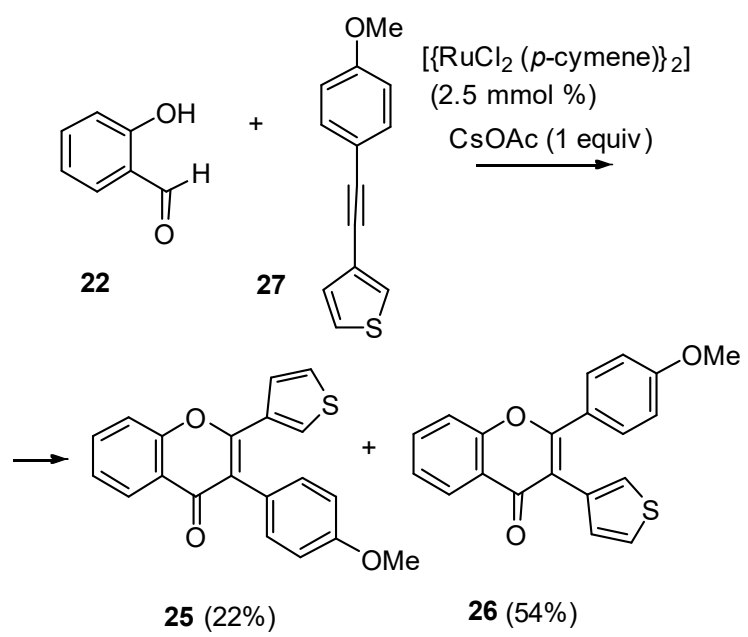

Scheme 8. The synthesis of 2-aryl-3-(3thienyl)chromone

2. Synthesis of 3-thienyl/benzothienyl chromones by introduction of an $S$ containing heterocycle to the chromone system

The classic way to obtain derivatives of 3hetarylchromones is the reaction of the interaction of 3-halochromone with derivatives of heteroarylboronic acid using a palladium catalyst.

The synthesis of the thienyl analogue of isoflavone 15 by the cross-coupling reaction of 3-iodochromone $\mathbf{2 8}$ with thiophenboronic acid 29 using tetrakis(triphenylphosphine) palladium as a catalyst in an argon atmosphere at room temperature was described in [11] (Scheme 9).

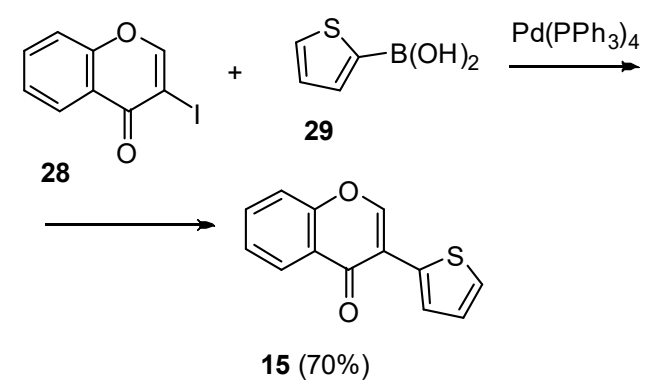

Scheme 9. The synthesis of 3-(2-thienyl)chromone
Using the Suzuki coupling reaction of 3halogenflavones $\mathbf{3 0}$ and $\mathbf{3 1}$ with heteroarylboronic acids $\mathbf{3 2}$ and $\mathbf{3 3}$ made it possible to obtain 2-aryl-3-(2benzothienyl)chromone $\mathbf{3 4}$ and 2-aryl-3-(2thienyl)chromone $\mathbf{3 5}$ with pharmacophore groups [12 ] (Scheme 10).
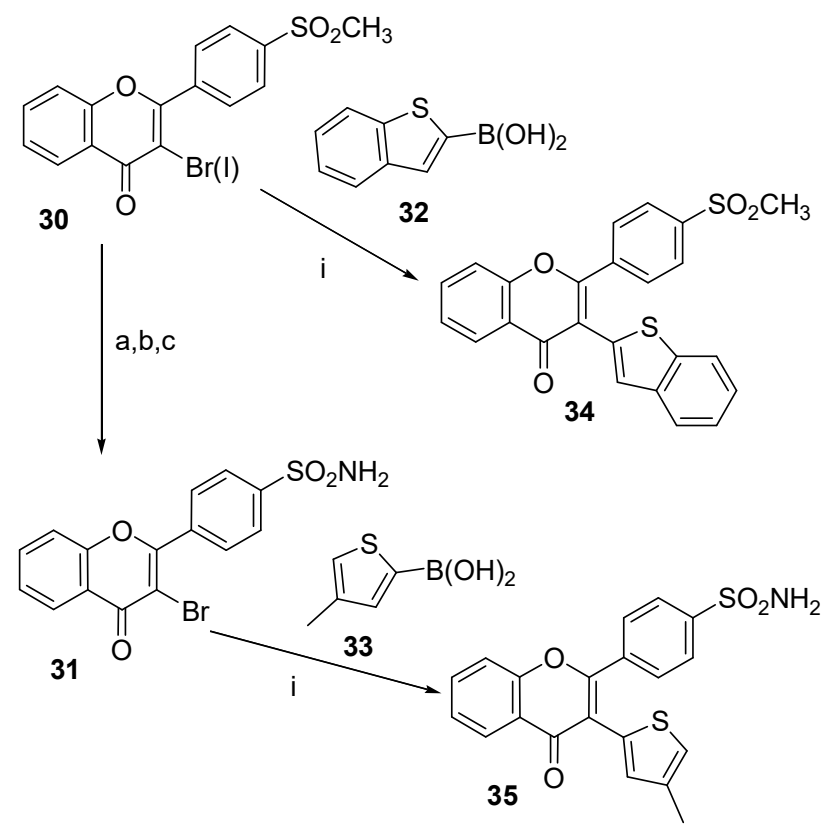

a: $\left(\mathrm{CF}_{3} \mathrm{CO}\right)_{2} \mathrm{O}$, reflux , b: $\mathrm{Cl}_{2}, \mathrm{AcOH} ; \mathrm{c:} \mathrm{NH}_{4} \mathrm{OH}$

i: $\mathrm{Pd}\left(\mathrm{PPh}_{3}\right)_{4}, 2 \mathrm{M} \mathrm{Na}_{2} \mathrm{CO}_{3}$, EtOH-H ${ }_{2} \mathrm{O}$-toluene

Scheme 10. The synthesis of 2-aryl-3(2thienyl/benzothienyl)chromones with pharmacophore groups

Claimed in the patent [13] 2-methyl-5,6,7trihydroxy-8-isobutyl-3-(2-

benzothienyl)chromone $\mathbf{3 6}$ was also obtained by the Suzuki reaction from a derivative of 3iodochromone 37 and benzothiophenboronic acid 32 when using the $\mathrm{Pd}(\mathrm{dpf})_{2} \mathrm{Cl}_{2}-\mathrm{CH}_{2} \mathrm{Cl}_{2}$ catalyst system and subsequent demethylation (Scheme 11). 


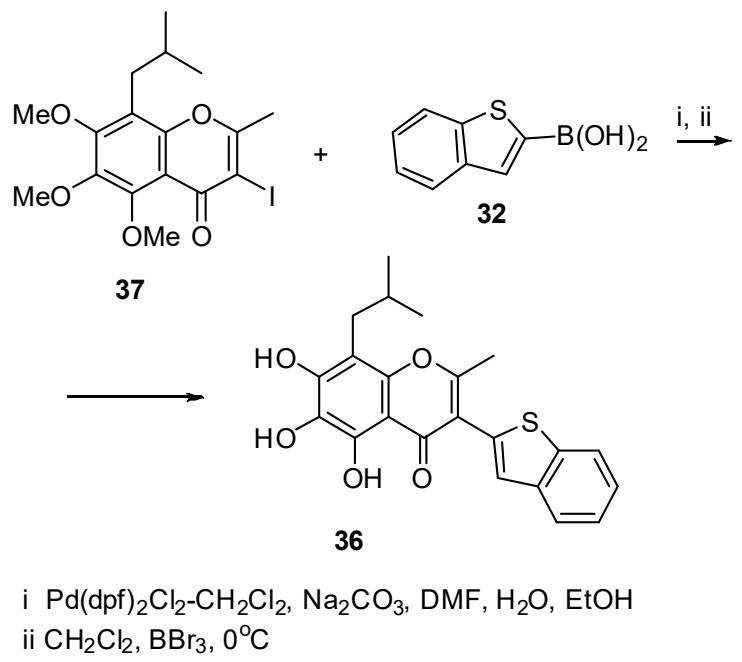

Scheme 11. The synthesis of 2-methyl-5,6,7-trihydroxy8-isobutyl-3-(2-benzothienyl)chromone

According to the Stille reaction, as a variant of the cross-coupling reaction, the interaction of (un)substituted 3-iodochromone and tetratiophenstannins in the presence of palladium on charcoal under mild conditions yielded (un)substituted derivatives of 3-(2thienyl)- and 3-(3-thienyl)chromones 38 [14]

(Scheme 12).

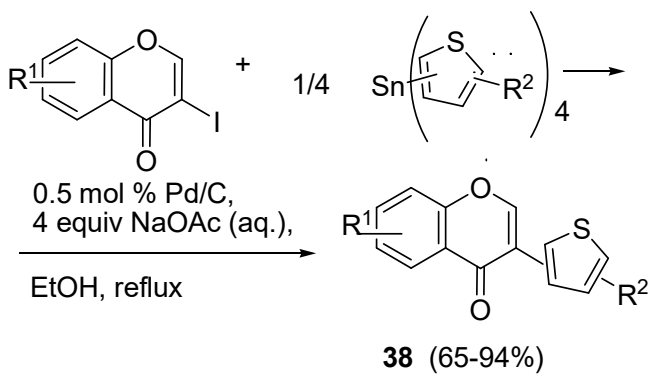

$\mathrm{R}^{1}=\mathrm{H} ; 6$ 6-F; 6-Br; 6-Me; 7-MeO; 7-i-PrO; 6-Cl, 7-Me $\mathrm{R}^{2}=\mathrm{H} ; 2-\mathrm{Me}$

Scheme 12. The synthesis of 3-(2-thienyl)- and 3-(3thienyl)chromones

In the direct coupling reaction of 3bromochromone 39 with (un)substituted thiophene 40 and 3-methylbenzothiophene 41 catalyzed by palladium, (un)substituted 3-(2thienyl)chromones 42 and 3-[2-(3- methylbenzothienyl)]chromone

were obtained [15] (Scheme 13).<smiles>O=c1c(Br)coc2ccccc12</smiles><smiles>[R]c1cccs1</smiles><smiles>[R]c1ccc(-c2coc3ccccc3c2=O)s1</smiles>

$42(38-72 \%)$

$\mathrm{R}=\mathrm{H}, \mathrm{Cl}, \mathrm{Me}, n-\mathrm{Bu}, \mathrm{COOEt}, \mathrm{C}(\mathrm{O}) \mathrm{Me}$ thien-2-yl, 1-methyldioxolan-1-yl
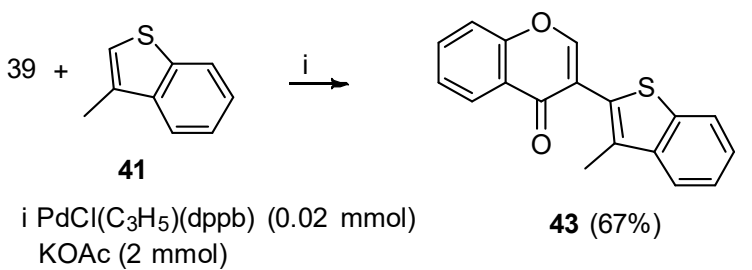

$43(67 \%)$ $\mathrm{KOAc}(2 \mathrm{mmol})$

Scheme 13. The synthesis of (un)substituted 3-(2thienyl)chromones and $3-[2-(3-$ methylbenzothienyl)]chromone

The synthesis of 3-(2-thienyl)chromones 44a-c by direct coupling of (un)substituted 3iodochromone with thiophene under the conditions of the photochemical reaction in acetonitrile under a high-pressure mercury lamp without any catalysts and bases was proposed in the works $[16,17]$ (Scheme 14).

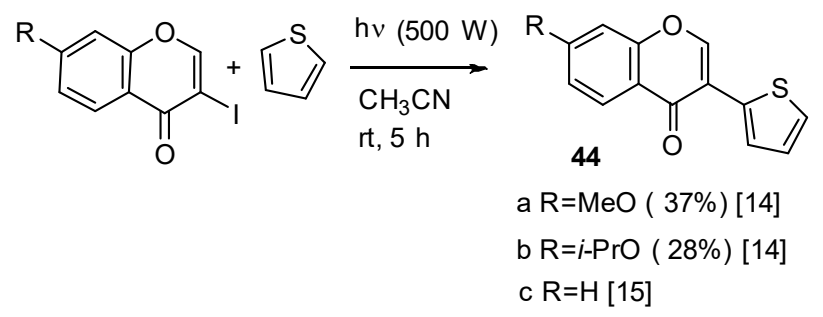

Scheme 14. The synthesis of 3-(2-thienyl)chromones

3. Chemical properties of 3hetarylchromones with S-containing heterocycles

Chemical properties are represented by a single example of the interaction of 3-(2thienyl)chromones $\mathbf{4 4 a , b}$ with hydrazine 
hydrate [17]. The reaction was carried out at a ratio of the reagents chromone : hydrazine hydrate 1:2 in boiling alcohol to obtain 3-aryl-4(2-thienyl)-1H-pyrazoles 45a, b (Scheme 15).

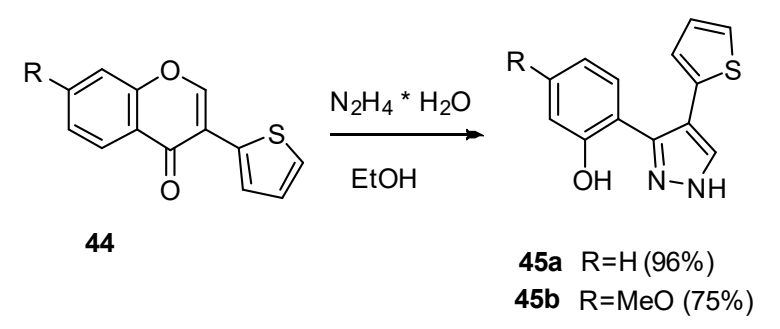

Scheme 15. The synthesis of 3-aryl-4-(2-thienyl)-1Hpyrazoles

\section{The biological activity of 3- thienyl/benzothienylchromones and their transformation products}

When searching for drugs with a higher therapeutic index and less toxic side effects, considerable attention has been paid to compounds of the thiophene series, which have a wide spectrum of biological effects, namely, analgesic, antimicrobial, antihistamine, antispasmodic, anticonvulsant, antiviral, anticancer, diuretic, pesticidal and others [18].

Recently, there have been many patent publications in which compounds of the thiophene and benzothiophene series are claimed to be selective modulators of estrogen receptors.

As for the thiophene analogues of isoflavones, according to the patents $[19,20]$, 5,7-dihydroxy-3-(2-thienyl)chromone (3) and 5,7-dihydroxy-3-(3-thienyl)chromone are ER- $\beta$ selective ligands having better selectivity compared to estrogen relative to estrogen- $\beta$ receptor compared to estrogen- $\alpha$ receptor and can be used in the treatment of diseases associated with the estrogen receptor- $\beta$, in particular, Alzheimer's disease, anxious disorders, depressive disorders, osteoporosis, cardiovascular disease, rheumatoid arthritis or prostate cancer. It should be noted that in an early review, the absence of estrogenic activity of 5,7-dihydroxy-3-(2-thienyl)chromon was reported [21].

In the extended patent family $[4,22] 5-$

(7-hydroxy-4-oxo-2-(trifluoromethyl)-4Hchromen-3-yl)thiophene-2-carboxylic acid (5) $\left(\mathrm{IC}_{50}<0.1 \mu \mathrm{M}\right)$ and 5-(7-hydroxy-4-oxo-2(trifluoromethyl)-4H-chromen-3-yl)thiophene3-carboxylic acid (6) $\left(\mathrm{IC}_{50}<1 \mu \mathrm{M}\right)$ are claimed to be inhibitors of S-nitrosoglutathione reductase and may be used in the treatment of diseases and pathological conditions associated with impaired NO balance, such as pulmonary hypertension, ARDS, asthma, pneumonia, pulmonary fibrosis, cystic fibrosis, chronic obstructive pulmonary disease (COPD), hypertension, ischemic radar syndromes, gastrointestinal disorders, inflammatory diseases, degenerative neurological disorders.

Current knowledge of the antiapoptotic Bcl-2 family role in cancer cells determine the targeting of this subfamily of proteins for therapeutic intervention in hyperproliferative diseases and malignant tumors. According to patent [13] in one embodiment 2-methyl-5,6,7trihydroxy-8-isobutyl-3-(2-

benzothienyl)chromone (36) is declared as 
compound that is an inhibitor of the antiapoptotic family $\mathrm{Bcl}-2$ and enhances cell sensitivity to apoptosis inducers, such as chemotherapy and radiation therapy, in animals.

To solve the problem of overcoming the multidrug resistance of tumor cells a series of asymmetric and symmetric benzodipyranones was tested in vitro as P-glycoprotein inhibitors [5] (Figure 1).<smiles>[R]c1coc2c(c(O)cc3occ([R])c(=O)c32)c1=O</smiles><smiles>[R]c1coc2cc3occ([R])c(=O)c3c(O)c2c1=O</smiles>

Figure 1. General formula of asymmetric and symmetric benzodipyranones

The test results revealed the structure-activity relationship of a series of $\mathrm{P}$-gp inhibitors and compound-leader. The symmetric benzodipyranones proved to be inactive. Asymmetric benzodipyranones with electrondonating substituents proved to be the most active (leader compound $\mathrm{R}=3$-methylphenyl), inhibition of P-gp activity was observed in compounds with electron-withdrawing substituents, compounds having thiophen-2-yl substituents (compound 11), 1-naphthyl, phenyl, cyclopropyl lost activity.

Currently, topical search for new classes of biologically active compounds COX-2 inhibitors, which are analogues coxibs in structure and action. Celecoxib (4-[5-(4methylphenyl)-3-(trifluoromethyl)pyrazol-1-yl] benzenesulfonamide) and rofecoxib (4-(4-
methylsulfonylphenyl)-3-phenyl-5H-furan-2one) have sufficiently high clinical efficacy comparable to the therapeutic (antiinflammatory and analgesic) effect of traditional NSAIDs, however, due to the high specificity of the inhibitory effect on COX-2 and the absence of influence on the COX-1 isoenzyme (responsible for the development of side effects when using NSAIDs) they have low gastrointestinal toxicity and lack of effect on platelet activity. Flavone derivatives with the necessary pharmacophore groups and (hetero)aryl substituents at the 3-rd position 3 of the benzopyrone backbone, which can conditionally be considered as coxib analogues in structure, were tested for the inhibitory effect on COX-2 [12]. The results of testing of compounds of this series made it possible to draw certain conclusions about the structureactivity relationship, and although some of the compounds (for example, compounds with a thienyl substituent $\mathbf{3 5}$ and a benzothienyl substituent 34) are practically inactive, and the highest activity was shown by the studied 2,3diarylchromones, although with significantly lower activity compared to coxibs, the search for COX-2 inhibitors among this class of compounds has a future.

\section{Tests of 3-(2-thienyl)chromone $\mathbf{4 4}$} transformation products under the action of a nucleophilic reagent - pyrazole compounds 45 in vitro, on antifungal activity against five phytopathogenic fungi (Cytospora sp., Colletotrichum gloeosporioides, Botrytis cinerea, Alternaria solani and Fusarium solani) 
showed that compounds 45a,b exhibit higher antifungal activity than the positive control of gimexazole against Cytospora sp., Colletotrichum gloeosporioides, Alternaria solani and Fusarium solani, however, they were almost inactive against Botrytis cinerea. The studied 3-aryl-4-(2-thienyl)-1H-pyrazoles 45a,b selectively inhibit the growth of Cytospora sp., Colletotrichum gloeosporioides. Thus, the growth inhibition rate of Colletotrichum gloeosporioides with an $\mathrm{IC}_{50}$ value of 12.86 $\mu \mathrm{g} / \mathrm{ml}$ of pyrazole $45 \mathrm{a}$ is much higher than the positive control of gimexazole $\left(\mathrm{IC}_{50}>100\right.$ $\mu \mathrm{g} / \mathrm{ml})$.

\section{Conclusions}

The considered methods for the synthesis of 3-thienyl/benzothienylchromones are quite simple and effective. The target products are mainly obtained with good and sometimes quite high yields. The directed functionalization of 3-hetarylchromones by introducing pharmacophore groups, such as $\mathrm{CF}_{3-}, \mathrm{SO}_{2} \mathrm{CH}_{3-}, \mathrm{SO}_{2} \mathrm{NH}_{2-}$, etc., as well as transforming into other heterocyclic systems, opens up wide possibilities for obtaining new substances, the spectrum of biological activity of which is significantly expanded and modified while maintaining a low toxicity level.

Due to the great importance of benzopyrones and thiophene in nature, medical chemistry and chemistry of materials, one hopes that the appearance of practically significant derivatives of 3-hetarylchromones with S-containing heterocycles is only a matter of time.

\section{References}

[1] Gronowitz S, Ekman R. Synthetic estrogenic isoflavonoids. 1. Synthesis of 3-(2'-thienyl)5,7-dihydroxychromone. Arkiv. Kemi. 1960;17(9):93-96; Chem. Abstr. 1961;55:27294

[2] Bumagin NA, Petkevich SK, Kletskov AV, Alekseyev RS, Potkin VI. Effective bimetallic composite catalysts for the synthesis of arylated furans and thiophenes in aqueous media. Chem. Heterocycl. Compd. 2019;55(6):508-516

[3] Primas N, Bouillon A, Rault S. Recent progress in the synthesis of five-membered heterocycle boronic acids and esters. Tetrahedron 2010;66(4):81218136

[4] Sun X, Qiu J; N30 Pharmaceuticals, INC. Novel S-nitrosoglutathione reductase inhibitors. WO patent 2011/100433. 2011 Aug 18.

[5] Chen C-Y, Liu NY, Lin HC, Lee C-Y, Hung C-C, Chang C-S. Synthesis and bioevaluation of novel benzodipyranone derivatives as P-glycoprotein inhibitors for multidrug resistance reversal agents. Eur. J. Med. Chem. 2016;118:219-229

[6] Justic MW, Zimmerman AK. Oxidative rearrangements of 2'-hydroxychalcones with 1H-1hydroxy-5-methyl-1,2,3-benziodoxathiole 3,3- dioxide. Heterocyclic Communications 2009;15(1):67-72

[7] Lin C-F, Lu W-D, Wang I-W, Wu M-J. Synthesis of 2-(Diarylmethylene)-3-benzofuranones Promoted via Palladium-Catalyzed Reactions of Aryl iodides with 3-Aryl-1-(2- tert-butyldimethylsilyloxy)phenyl-2-propyn-1-ones. Synlett 2003;(13):2057- 2061

[8] Liu H, Yang Y, Wang S, Wu J, Wang X-N, Chang J. Synthesis of 3-Substituted 2Aminochromones via Sn(IV)-Promoted Annulation of Ynamides with 2-Methoxyaroyl Chlorides. Org. Lett. 2015;17(18):4472-4475

[9] Shimizu M, Tsurugi H, Satoh T, Miura M. Rhodium-Catalyzed Oxidative Coupling 
between Salicylaldehydes and Internal Alkynes with $\mathrm{C}-\mathrm{H}$

Bond Cleavage To Produce 2,3-Disubstituted Chromones. Chem. - Asian J. 2008;3(5):881-886

[10] Baruah S, Kaishap PP, Gogoi S. Ru(ii)Catalyzed $\mathrm{C}-\mathrm{H}$ activation and annulation of salicylaldehydes with monosubstituted and disubstituted alkynes. Chem. Commun. 2016;52(88):13004-13007

[11] Yokoe I, Sugita Y, Shirataki Y. Facile synthesis of isoflavones by the cross-coupling reaction of 3-iodochromone with arylboronic acids. Chem. Pharm. Bull. 1989;37(2):529-530

[12] Joo YH, Kim JK, Kang S-H, Noh M-S, Ha J-Y, Choi JK, Lim KM, Lee CH, Chung S. 2,3Diarylbenzopyran derivatives as a novel class of selective cyclooxygenase-2 inhibitors. Bioorg. Med. Chem. Lett. 2003;13(3):413-417

[13] Wang S, Ding K, Tang G, Wang R, Yang C, Nikolovka-Coleska Z; Univ Michigan. Chromen-4-one inhibitors of anti-apoptotic bcl-2 family members and the uses thereof. WO patent 2006/99193. 2006 Sep 21.

[14] Yang Q, Zhang Z, Liang B. Synthesis of 3-Thiophenchromone by Stille Cross-coupling Palladium on Charcoal-Catalyzed Ligand-Free. J. Heterocycl. Chem. 2015;52(1):310-316

[15] Belkessan F, Derridj F, Zhaj L, Elias A, Aidene M, Djebbar S, Doucet H. Pd-catalysed heteroarylations of 3-bromochromen-4-one via $\mathrm{C}-\mathrm{H}$ bond activation of heteroarenes. Tetrahedron Lett. 2013;54(36):4888-4891
[16] Yang Q, He Y, Wang T, Zeng L, Zhang Z. Synthesis of 3-heteroarylchromones via a photochemical reaction. Mol. Divers. 2016;20(1):9-16

[17] Zhang J, Tan D, Wang T, Jing S, Kang Y, Zhang Z. Synthesis, crystal structure, characterization and antifungal activity of 3,4-diaryl-1H-Pyrazoles derivatives. J. Mol. Structure 2017;1149:235-242

[18] Shah R, Verma PK. Therapeutic importance of synthetic thiophene. Chemistry Central Journal 2018;12:137 https://doi.org/10.1186/s13065-0180511-5

[19] Barlaam BC, Piser TM; Astra Zeneca AB. Estrogen receptor- $\beta$ ligands. United States patent 6518301. 2003 Feb 11.

[20] Barlaam BC, Piser TM.. Estrogen receptor-beta ligands. WO patent 2000/62765. 2000 Oct 26.

[21] Nobles L.W, Blanton DeWitt C. Thiophene Compounds of Biological Interest. J. Pharm. Sci. 1964;53(2):115-129

[22] Sun X, Qiu J, Stout A. N30 Pharmaceuticals, INC. Compounds as Snitrosoglutathione reductase inhibitors. WO patent 2012/170371. 2012 Dec 13. 